Published in Sport, Ethics, and Philosophy, 6, 3 (2012): 353-368.

10.1080/17511321.2011.652661

\title{
Different Kinds of Perfect: The Pursuit of Excellence in Nature Based Sports
}

\author{
Leslie A. Howe
}

\begin{abstract}
Excellence in sport performance is normally taken to be a matter of superior performance of physical movements or quantitative outcomes of movements. This paper considers whether a wider conception can be afforded by certain kinds of nature based sport. The interplay between technical skill and aesthetic experience in nature based sports is explored, and the extent to which it contributes to a distinction between different sport-based approaches to natural environments. The potential for aesthetic appreciation of environmental engagement is found to be strongly dependent on whether or not environmental engagement is exploited for the end of producing a quantifiable result or enhancing technical skill. It is also argued that an existential rather than spectatorial attitude to aesthetic experience is offered by specifically nature oriented sport. Aesthetic experience achieved in this way is therefore neither passive nor detached, but extends Berleant's concept of participatory environmental aesthetics and underpins both an alternate (wide) conception of excellence in sport activity and a richer experience of aesthetic engagement than more objectivised standpoints.
\end{abstract}

The pursuit of excellence is a constitutive aim of sport. This is not a (very) contestable claim in itself, but it masks what is highly contestable, namely, what precisely it is that constitutes excellence in sport. Normally, excellence is taken to be measurable in at least one of its aspects, although the precise means of measurement or elements to be measured may be subject to dispute (as in judged sports). In conventional urban based sports, excellence in performance is commonly taken to be a matter of superior performance of a more or less constrained set of physical movements or, preferentially, the outcomes of such movements. These outcomes may be internal to a given sport practice, such as wins, goals, points, and the like, or external, such as revenues, fan base, or brand recognition. Some, myself included, would dispute this assessment and assert that sport isn't only a matter of wins, goals, and medals, but that sport excellence is a complex achievement, comprising not only the quantifiable but the qualitative reflection of sport practice in the development of self and the subjective experience of bodily movement and expression for both participant and engaged observer. These qualitative aspects include what we may designate the characteriological, the phenomenological, and the aesthetic, among others.

The present paper undertakes two main tasks. First, I shall consider some complications for the conception of sport as the pursuit of excellence where such sport is practised in "natural" environments; in particular, I argue that where excellence is narrowly construed as the expert exercise of sport specific technical skills the qualitatively "natural" aspect of the environment in 
which nature-based sports are pursued becomes of diminishing relevance. Second, I counterpose to the narrow conception of sport excellence one that validates the aesthetic experience of natural environments through engaged (sport) activity. This conception of sport-based aesthetic is one that emphasises participant rather than spectator experience, and thus requires an aesthetic stance that is more existential than disinterested. Finally, I arg ue that such an engaged aesthetic experience of and in natural environments offers a more rounded conception of sport excellence than that offered by the single-minded chasing after numbers and records.

\section{Urban and Natural Sport}

Urban based sports (UBSs) are those that are most readily identifiable, especially by philosophers of sport, as sports; they include games and those sports that require measured and reproducible conditions (tracks, etc.). UBSs are commonly, though not necessarily, competitive. Their defining characteristic, however, is their artificiality, in that they are structurally determined by the setting apart of a conventional world of play, and of time or space, suspended in a provisional sort of way from that of everyday existence. All sports are conventional constructions in some respect, but UBSs are especially so as they are at a fundamental level formal, abstract "worlds" with no fixed geographical location. These "worlds" may be physically represented by concrete structures such as a pitch, track, or gymnasium, or the like, but an UBS can, in principle, be played anywhere so long as its formal conditions are met, say, that it be played within a certain span of time, or that there be so many players a side, or that the game ends when one side gets 21 points in the prescribed way, etc. Although any given instantiation of an UBS will necessarily have a physical location, and although there may be aspects of that actual location that may affect how that competition proceeds (e.g., altitude), those circumstances do not alter that sport as definitionally an instance of that sport. The formal conditions entail the fundamental irrelevance of actual location: the sport can be played anywhere that these formal conditions can be met or reasonably adapted. Such sports are, at their extreme, understandable independently of the contingency of their performance in actuality. ${ }^{1}$

Prima facie it would seem reasonable to distinguish urban based sports from nature based ones, where the latter are those sports that have as a central or essential component some component of the natural environment. This component is non-substitutable in the minimal sense that the sport cannot be carried out without it, but the required "natural" component may be generic rather than specific (e.g., snow, but not necessarily the snow on mountain X) and may in many cases be artificially adapted or provided (e.g., artificially produced snow). Thus, downhill skiing at a fully equipped modern resort is certainly a nature based sport in that it requires snow and a big slope, which ordinarily also means appropriate geographical conditions. But in view of the quantity of artifical infrastructure, and the at least theoretical possibility of constructing an entirely artificial environment in which it could be carried out, we might also consider it a relatively urban sport. Likewise, competitive rowing, canoeing, and kayaking require water with particular characteristics but can be done on an artificial basin in direct proximity to urban centres.

${ }^{1}$ Baseball is perhaps a particularly striking example of this, since any actual game can be (almost) fully described by its box score. 
Clearly, the naturalness of the natural component in NBS can be very minimal and the sport, as the sport it is, may be concerned with eliminating much of this component's naturalness, as when the sport's competitive stress is on ensuring equality of competitive conditions (e.g., speed-skating). In such cases, we may be right in thinking that the sport in question has only an incidental relation to any feature of the natural environment. Moreover, a significant number of NBSs, although they require some natural environmental feature as their central component, are otherwise structured in much the same way as UBSs-they are basically UBSs with an extra condition: competition is either assumed or anticipated, time and/or distance circumscribes activity, and the development of technical skill becomes an overriding concern. At the same time, however, there are nature based sports in which the specific features of the natural environment in which the sport is pursued are central to the pursuit.

Because of these considerations, it might be thought that the UBS-NBS distinction is ultimately too vague to bear much philosophical weight by itself. Consequently, we must make a further distinction of NBS into what I shall call Nature Instrumental Sport (NIS) and Nature Directed Sport (NDS), with NDS comprising Nature Specific Sport (NSS), and Nature Oriented Sport (NOS). ${ }^{2}$

\section{Using Nature for Sport}

Any sport requires awareness of and response to its own specific environment. This is evident in games: the player must be able to anticipate and react to the moves of the opponent. In NIS, one not only has opponents to contend with but a dynamic natural environment. This dynamic quality can be of particular significance. Ordinary playing venues are more or less fixed and must be to be fair. While fairness is no less important in NIS, the fact of it being placed in an environment that is subject to natural, perhaps constant, variation, both in respect of time and extent, means that the competitor/participant must be able to notice, to assess, and to make a suitable adjustment to these variations. This may require a change in equipment, technique, or strategic approach. All these require technical skill. In this respect, then, it is arguable that NIS requires a further layer of technical skill over UBS, even when a given UBS demands flexibility of approach to changing competitive conditions. Simply, NIS incorporates an additional competitive component (“opponent") that tests the participants' technical excellence.

I do not claim that NIS is, because of this, inherently more difficult on a technical level, though this may in some instances prove to be the case; what I am claiming is that the circumstance of being placed in a dynamic natural environment (over and above a dynamic human environment) rather than a fixed and largely artificial one presents a problem for the participant-competitor that is not significantly present in UBS and that demands a technical

\footnotetext{
${ }^{2}$ The reason for making these distinctions is primarily philosophical clarity, but there are practical motivations as well. If we aim to make philosophically plausible arguments in favour of preservation of some natural area on the ground that it offers valuable potential for human engagement with nature through recreational pursuits such as skiing, hiking, paddling, and the like, we should be clear whether these pursuits really do offer potential for such engagement. Put more bluntly, is preserving a "wilderness" area for a ski resort or white water park that different from razing it to build a hockey arena or skateboard park? Giving a philosophical answer to this question requires being clear about exactly what sport or environmental benefits are to be obtained from a given type of sport activity.
} 
response, one that, moreover, is based in an understanding of that natural feature or environment. Thus, the paddler needs to understand something of hydraulics in order to get through all the gates clean, the nordic skier something of the interaction between temperature, humidity, and snow crystal formation in order to apply the right wax that will ensure the correct balance between grip and glide for speed, and so on. This secondary layer, then, has two components: knowledge of the environmental background and knowledge how to respond to it instrumentally. ${ }^{3}$ Knowing what the terrain is like, what happens to it if there is rain overnight, how sandy or clayish the soil is, how steep the inclines are, etc., allows the mountain biker to determine the appropriate tires and pressure to use, when precisely to brake, in order to complete the course faster than her opponents and so to win.

This also indicates the crucial point in distinguishing NIS from other kinds of NBS. NIS differs from UBS in having this essential stress on its natural component, but NISs relate to that natural component in an instrumental way: given $\mathrm{x}$, how do I use it effectively in order to win? In this respect, we might say that the natural environment has become accidental even though essential-mountain bike racing isn't about mountains but about going faster than other mountain bikers on mountains. In this respect, although NISs possess this important connection with the natural and so are properly designated as NBSs, they are in many respects, just UBSs in more interesting and challenging locations. Having said this, I don't want to dismiss the wider potential of the environmental component in NIS. Since success requires understanding of the critical environmental elements, NIS can be a catalyst for greater personal interest in the natural environment in which the sport is carried out beyond what is instrumentally required for sport success. For example, rowing is normally conducted as an NIS: rowers compete in highly technical equipment, racing and training by going back and forth repetitively in lanes, their performance closely monitored for improvement or failure. The water on which they race is ideally devoid of any natural characteristic at all (i.e., dead calm). To encounter a variation in water or weather in the middle of a race is undesirable, and the rower's body should be a perfectly tuned machine, performing an unrelenting, unvarying, metronomic movement. Yet, the same rower can also take a shell along a quiet natural river as the sun comes up, watching the foxes trotting along the shore, the flotillas of goslings trailing behind their parents, kingfishers and terns diving, at the same time as they feel through their oars and the pull of the boat beneath them the varying flows, eddies, and swirls of the water through which they move themselves. NIS opens a window; the participant may or may not look through it. Insofar as the participant's focus is on competitive success, however, and the development of environmental expertise is directed to the advancement of sport defined technical skill in relation to the specific environmental or natural feature, there may be decreased incentive to "look through the window".

\section{Nature Directed Sport}

It is important to note that while nature based sports may be pursued with a relative

\footnotetext{
${ }^{3}$ It would be easy to overstate just how much knowledge is required in any given case; this will be variable and may often be minimal and a matter of intuitive familiarity while other cases may require considerable reflective technical expertise.
} 
lack of skill, many are more enjoyable and, it should not be underestimated, survivable, if the participant has acquired certain sport-relevant skills: ordinary physical competence and fitness, navigational skills, weather awareness, and so on-indeed, a good many of the same skills called for in UBS and/or NIS. Of course, anyone can go for a walk in the woods, but it is perhaps a mark of the relative lack of regard for nature directed sports as sports that so many go totally unprepared for a stroll in the hills when they would not dream of being so cavalier about stepping onto a rink or a pitch. Nevertheless, these sports do, just as much as other sports, demand a degree of technical skill from their participants and it is in part because one can develop high degrees of physical excellence in such sport specific activities that we call these sports.

The class of nature based sport activities that concern us here are those that demand some (often a high) degree of physical and technical skill and that are largely noncompetitive, at least in the sense and degree to which UBS and NIS are. Such sports are more open-ended and variable in that, although participants normally set themselves goals (such as routes), these goals are generally revisable without failure and performances are more resistant to simple repetition. By "nature directed sport" I mean nature based sport that has as a central or essential component some feature of the natural environment (as does NIS), but in which the activity is directly concerned with that natural feature and in which the naturalness of the environment is not substitutable for some artificial analogue. Put simply, mountaineering is a nature directed sport because it can only be done on genuine mountains, as well with the methods constitutive of the practice of mountaineering.

Within nature directed sport, there is a spectrum of concentration, with some activities concentrating more heavily, even exclusively, on sport experience and others having a stronger emphasis on certain kinds of environmental experience. The former I designate nature specific sport (NSS), as it is emphatically sport that is directed to a specific natural feature and seeks characteristically sportive experiences in relation to that feature, i.e., ones having to do with the perfection of physical and technical skill and experience. Nature oriented sport (NOS), while requiring attention to the skills implicated in NSS, and possibly deeply concerned with development of them, is more decisively motivated by the desire for aesthetic experience of the natural environment within which the activity is performed and may also direct attention to a wider segment of the natural environment than can be taken in by the nature specific sportsperson at a given moment. While some nature directed sport activities may be obviously either NSS or NOS, I think it probable that there will be many instances where this is undecidable without determining the particular aims and practices of the participants themselves. Iceclimbing seems a likely candidate for NSS and hiking for NOS, on the grounds that an ice-climber is likely to be so absorbed by the technical and physical problems presented by a particular section of a climb that he has no mental time for anything other than determining where to put his picks and how far he can reach on the next move without falling off, while the stereotypical hiker has an abundance of leisure to look about and smell the peat. But it is entirely possible for an ice-climber might climb to satisfy an aesthetic appreciation for the qualities of ice. Likew ise, a hiker might spend every available free day in the hills out of a determination to improve her backcountry efficiency, by increasing the distance she can cover in a day, the loads she can carry, improving her skills in backcountry medicine, constructing shelters, and interpreting weather. 
She might do all this in order to bag all the munros within a set number of years. ${ }^{4}$ There is not a clear-cut distinction to be made here with regard to which sports fall on one side or the other; whether an activity ought to be characterised as NSS or NOS will depend more on the type of experience sought by the participant than the precise range of physical movements required by the sport.

Moreover, any given participant may have multiple goals: to both exercise and perfect technical skill and experience the natural environment in which they are exercised. The earlier discussion of NIS suggested a conflict between technical skill and (nature based) aesthetic experience. The tension remains in the NSS-NOS spectrum, to possibly more dramatic effect in that inattention to technique may have much more radical consequences than simply losing a race, but it is also the case that the participant in nature directed sport has, in general, a greater freedom to pause and appreciate than the cross country sprint racer. Nevertheless, there is a tension as well in the circumstance that while skill is needed to get oneself into and out of the environment that is thus opened up to one for experience, and to understand and appreciate that environment, an exclusive concentration on skill has one miss, in a sense, the environment one has taken such pains to enter.

What makes NDSs, but especially NOSs, different from the other varieties of sport is that, as important as technical excellence is, it is not the only excellence at play. ${ }^{5}$ Moreover, although some NOSs may call for extremely high levels of skill, and although for some participants skill development in and of itself, independent of any competitive impulse, may be a permanent concern, all these may take an ancillary role in relation to a particular kind of aesthetic experience, i.e., of excellent bodily movement and engagement with a natural environment. NOS is, above all, sport oriented to experience in and of nature, and self in nature, rather than winning in the use of nature.

In UBS and NIS, excellence is more readily measured in terms of competitive achievement; one performance is better than another because of objectively measurable factors. The additional aesthetic layer in NOS experience (and to a lesser extent NSS) reshapes what counts as excellence in this kind of sport. Simply, what makes a perfect hike is not what makes a perfect $10 \mathrm{~km}$ cross country race, nor a perfect game. This is not to say that there are no smaller goals in NOS-one always sets out to do something: to climb a specific mountain, paddle a route, or to have a satisfying sport experience (e.g., to feel fluidity in one's movements or exhaustion at the end of the day). But the content of such goals is more likely to be defined by the overall experience of following that route than it is of, say, bettering one's previous time or beating someone else to it, though these considerations may well have their influence in specific cases. Additionally, failure to achieve these set goals does not necessarily amount to failure

\footnotetext{
${ }^{4}$ I am including hiking as a sport here on the grounds that it does suppose perfectible or at least improvable skills; I am excluding mere perambulation of the sort that leads t-shirted individuals to grief on Snowdon and Ben Nevis. My thinking about this issue and those immediately preceding have been sharpened by discussions with Kevin Krein. ${ }^{5}$ I don't think this is the whole story about excellence in sport, as I noted in the Introduction to this paper, but since UBS, NIS, NSS, and NOS all share an interest in the other forms of excellence that I contend are involved in sport (such as the characteriological), I shall for present purposes pass over these other factors.
} 
overall-some of the best hikes may fail to reach their projected targets on the map. In sum then, the climber, the scrambler, the hiker, and the fell-runner engage with a hill-path in quite different ways, although each is doing NBS that depends crucially on the same natural environment.

\section{The Aesthetic in Sport}

When the aesthetic is discussed in connection with sport it is usually done so from the external perspective of the spectator and is concerned with the effect of the performance on the spectator. I shall have nothing to say about such external assessments. Rather, my concern here is to shift attention to the subjective experience of the sport participant. If we confine our attention to this, the aesthetic centres in two primary areas: the subjective lived experience of

(1) the body itself in movement, and

(2) as a body actively engaged with, i.e., in relation to, a physical environment. This latter can be either or both:

(a) other participants (UBS and NIS) or

(b) some natural environment or feature (NIS, NSS, NOS).

Accounting for the participant's subjective apprehension of sport activity requires interpreting "aesthetic" in terms that have less to do with the epistemological and evaluative concerns of contemporary philosophy of art than with existential ones about the individual's orientation to self and engagement. For any sport, a central feature of it as sport is the lived experience of the participant's own body in movement; indeed, it is this movement that makes it sport and awareness of movement as one's own, the body-mindedness of immersion in movement, is of decisive importance in developing expertise in that movement. Sport operates at the level of the sensuous: it demands the sensory and it relies heavily upon the emotional; it begins with and strives to recapture immediate feeling and response. Sport requires bodily movement not only because it is about physical exercise or even about producing physical shapes pleasing to the eye of the observer; it is in bodily expression and dynamic corporeal interactivity that we experience what draws us to sport, namely, play.

Play is a way of making aesthetic immediacy the focus of consciousness. In sport and play we seek the immediacy of bodily expression and the reflective satisfaction of doing so in a particular way. The kind of experience sought in such activities is, I contend, aesthetic in a Kierkegaardian sense, in that the ideal of movement as "flow" is one that is not only effortless but reflectively impervious. That is, the experience of movement for which training prepares the sportsperson is one in which the sportsperson is their movement, in which intention translates apparently seamlessly into result, in which the subjective experience of self and world is of perfect immediacy. In more prosaic terms, "being in the zone" is a description of an aesthetic experiential ideal. Alas, most sport and a great deal of play is not experienced in this way although the promise of such perfect moments may be what keep many in their otherwise imperfect pursuit. Reflectivity, however, does not by itself cancel the aesthetic and it is here that the Kierkegaardian perspective on the aesthetic is especially useful.

Kierkegaard's depictions of aesthetic existence in his pseudonymous works are sometimes of an immediate but more often of a reflective aesthetic stance. The reflective 
aesthete is committed to a life spent pursuing "the interesting" as well as more conventional objects of aesthetic enjoyment (including philosophy); the difference is that this sort of aesthete does not merely enjoy but reflects on his enjoyment, or on himself in his enjoyment ${ }^{6}$, and deliberately contrives means to facilitate such enjoyment. Kierkegaard's purpose in presenting such personalities is not to endorse their existential orientation-quite the contrary-but, for Kierkegaard, the aesthetic sphere of existence is not something to be abjured; it is a sphere in which we all continue to exist because we have bodies and exist in time. Although an especially intellectualised aesthete may seek out and develop theories of art, any actually existing human individual takes an inevitable and legitimate interest in sensuous pleasure, beautiful scenes or music, and cunningly humourous turns of phrase. ${ }^{7}$ This is not simply sensory awareness, but an attitude of aesthetic interest in relation to such awareness. Thus, walking briskly to work is not necessarily an aesthetic pursuit, but walking in preference to taking the bus in order to have a particular kind of sensory experience, perhaps to savour the warmth of sunlight, the movement of underused leg muscles, and the chatter of birdsong rather than the cacophony of mobile phone ringtones and the sickening lurching of the bus, would be a decision in favour of (a particular) aesthetic experience. Unless such a basic level of aesthetic experience is available to us as a motivated experiencing, there would be no further incentive to theorise about such experiences and transform them into either art or disciplinary aesthetics. But what I would also call attention to is the emphasis that Kierkegaard's aesthetes place on their environment: the circumstance that they seek not just beautiful objects to which to attend, but they seek them in specific environments, and frequently to engage with them in those environments, or with the environments themselves. They are concerned with ideals, yes, but those ideals are often themselves, or placed within, complex interactional situations.

This last point is crucial. The aesthetic does not occur outside of some environment-it is precisely a relation to environment. Likewise, even so-called "individual" sports are not done in Cartesian isolation: they necessarily involve some kind of interaction within a physical context, as well as a social one. ${ }^{8}$ In UBS, that environmental context is primarily other real or hypothetical participants. In NBS, there is some feature of the natural world that also (NIS/NSS) or primarily (NOS) takes this role. In no sport, however, does the participant get to simply bask in the flood of sensuous information around him or her, but is required to focus on select parts of the bandwidth. Competitive sports, in particular, require a ruthless attitude to one's own experience. The trick is to filter this information in a useful way. For example, if one's purpose in participating in NIS activity is success in the activity itself, where this is defined in terms of

\footnotetext{
${ }^{6}$ See Either/Or, Part I, p. 305, “A"'s assessment of Johannes the Seducer: "The poetic was the plus he himself brought along. This plus was the poetic he enjoyed in the poetic situation of actuality; this he recaptured in the form of poetic reflection. This was the second enjoyment, and his whole life was intended for enjoyment. In the first case, he personally enjoyed the esthetic; in the second case, he esthetically enjoyed his personality."

${ }^{7}$ See Postscript, 472ff. On the other hand, an orientation to the aesthetic that becomes definitive of one's self to the detriment of one's capacity to take notice of one's responsibility for oneself is, on Kierkegaard's model of selfhood, ethically (and religiously) defective. The relevance of this disjuncture for sport is that the sensuous experience of play and athletic endeavour is entirely justifiable as a legitimate expression of our existential condition, just as is the pursuit of aesthetic excellence and experience in art and music, but that both fall away in face of our ethical obligations. Thus, a game that at one moment seemed to be a matter of life and death, becomes suddenly trivial when actual life and death are implicated-or else something has gone seriously wrong at the ethical level.
}

0.This is why not all games, chess or World of Warcraft, for example, are sports. 
winning or achieving superior objective results as defined by the constitutive aims of the sport in question, then one has a positive incentive not to get distracted by any feature of the environment in which one is competing that does not have a directly instrumental effect on achieving those aims. For example, noticing the beautiful natural setting around the lake on which one is training oneself in a complex movement is a good way to fail in one's training. In this respect, success in NIS demands a relative withdrawal of attention away from sensory information that does not possess instrumental value. ${ }^{9}$ This may leave room for feeling the joy of movement (say, gliding easily) but it like as not closes the window on enjoying the environment through which one moves for its own aesthetic qualities beyond what one needs to know; at the very least this is constrained.

In this respect, it seems reasonable to say that although sport in general is an aesthetic pursuit, and although some sports (nature based ones) open up additional possibilities for certain kinds of aesthetic experience, i.e., of the natural world as well as the human, certain of those sports also forestall a deep and more thorough aesthetic exploration of their constitutive environments. In less convoluted language, NISs are caught in an experiential bind: they open the window to environmental experience but must then close it again in order to get on with winning. Where this happens, the exercise of technical skill and competitive excellence limits development of another kind of excellence.

\section{Environmental Aesthetics}

The passivity of immediate aesthetic experience is a characteristic that marks much of the traditional and contemporary aesthetic attitude to nature. Whether we consider late $18^{\text {th }}$ century ideas about the "picturesque" and romantic notions of sublime mountain landscapes, or the modern tourist driving to the lookout point to get the perfect photograph, one's activity in the aesthetic endeavour is largely expended in getting to the beautiful spot in order to gaze upon a landscape that is superficially laid out before one as a surface, over there. For some, there may be further "activity" expended in reflecting and theorising upon either the subjective affect or the objective structures in the scene that trigger these responses; this is what Kierkegaard's reflective aesthetes do, and they are very busy about putting events and themselves into exactly the right position so that they can sit back and observe these reflectively satisfying results; knowing how rightly to reflect on what one perceives allows one the maximum aesthetic appreciation of the aesthetic object. ${ }^{10}$ It does also seem to characterise a great deal of contemporary writing on environmental aesthetics.

In many ways, the debate in environmental aesthetics between cognitivist and noncognitivist theories of appreciation echoes Kierkegaard's distinction between reflective and

\footnotetext{
${ }^{9}$ The very accomplished may be able to open up attention to the instrumentally extraneous, but this depends on individual and specific competitive conditions.

${ }^{10}$ The major disanalogy here is that Kierkegaard's pseudonyms " $\mathrm{A}$ " and Constantine Constantius are concerned only with "the interesting", a somewhat metaphysical category (though no less aesthetic for that), directed to the potential in a human being for spiritual conflict, development, and ideal representation. Consequently, these aesthetes, while not unmoved by natural beauty, do not rate it highly.
} 
immediate aesthetic, with much of recent discussion defending immediacy of experience against the knowledge based aesthetic of Allen Carlson in particular. Carlson argues that sound aesthetic appreciation of nature requires a scientific (or at least a naturalist's) understanding of the parts of nature that one is viewing.

"[I]n the case of the natural environment the relevant knowledge is the common sense/scientific knowledge that we have discovered about the environment in question. This knowledge gives us the appropriate foci of aesthetic significance and the appropriate boundaries of the setting so that our experience becomes one of aesthetic appreciation. If to aesthetically appreciate art we must have knowledge of artistic traditions and styles within those traditions, then to aesthetically appreciate nature we must have knowledge of the different environments of nature and of the systems and elements within those environments. In the way in which the art critic and the art historian are well equipped to aesthetically appreciate art, the naturalist and the ecologist are well equipped to aesthetically appreciate nature.” (Carlson (2004): 71-2)

Moreover, we need to approach different environments differently; a prairie landscape calls for a survey of contour and slowly shifting and subtle colours, whereas a rain forest requires detailed scrutiny of its multitudinous elements. "Different natural environments require different acts of aspection; and as in the case of what to appreciate, our knowledge of the environment in question indicates how to appreciate, that is, indicates the appropriate act or acts of aspection" (Carlson 2004, 72).

What we know, then, of a given natural environment tells us how to appreciate it aesthetically. Carlson uses the example of a rorqual whale, "a graceful and majestic mammal. However, were it perceived as a fish, it would appear more lumbering, somewhat oafish, perhaps even a bit clumsy (maybe somewhat like a basking shark)" $(2000,89)$. One reason this is important, in Carlson's view is that

"Appreciating objectively in this sense is appreciating the object as and for what it is and as and for having the properties it has. It is in opposition to appreciating subjectively in which the subject-the appreciator-and its properties are in some way imposed on the object, or, more generally, something other than the object is imposed on it." $(2000,106)$

Much environmental thinking has placed a strong critical emphasis on the tendency to read the human into nature, not only in using nature as allegory for the human (Slater, Merchant), but seeing the natural world in terms of human conceptual-cultural constraints such as "wilderness" (Cronon), or attempting to form it as we do artefacts, in the way $18^{\text {th }}$ century ideals of the "picturesque" contrived to do, and interpreting nature on the model of linear and anthropocentric narratives (Foster). Such approaches treat the natural world as inchoate object, given intelligible form by human activity. Such a view of nature might perceive it as very busy in one sense, much in the way an ant-colony is busy, but not itself active or capable of action-we act in relation to it, especially by using it and by understanding it, bringing it into human conceptual and scientific structures, and also by appreciating it aesthetically. Carlson certainly seems to be pushing against this attitude, as is Yuriko Saito, who is concerned with developing 
moral criteria for the appropriate appreciation of nature. ${ }^{11}$

Other, noncognitivist, approaches push against this weight of historical attitudes as well, but by rejecting the intellectualised line taken by Carlson and Saito. Some argue that this approach still effects a distortion of nature as it is in itself and that a proper appreciation of the natural, aesthetic or otherwise, would have us simply listen to what it has to tell us, without imposing such structures upon it. That is, instead of objectifying nature, holding it apart by categorising and reducing its phenomenal directness to human epistemological-scientificinstrumental terms, we need to experience it fully surrounding us, in a multisensuous, moodful way (Foster, 208). These two approaches are in certain respects much the same; both are passive in the respect that the human subject confronts nature in the mode of sensory receptor. Carlson's proposal that one approach the aesthetic object with knowledge based in the natural sciences gives the impression of requiring that the appreciator take on an active role in relation to an environment or feature of the natural world, in that one must not simply take in sensation but directly interpret what is observed in order to have a (well-founded) aesthetic experience. This "activity", however, is relative and remains essentially at a reflective, intellectual, level. Whether aesthetic appreciation is an immediate, ambient (Foster), emotional (Carroll) experience or an imaginative (Hepburn, Brady) or narrative reflection (Heyd) on natural experience, the natural environment is in all cases largely understood in terms of something one looks at, listens to, feels around one, and perhaps then reflects upon. Even if one can only appreciate the sensuously beautiful movement of a whale if one understands that it is a mammal rather than a fish, one is still beholding the natural world as an external play of sensations, which one then appraises as to its beauty or lack of same. The world remains on view, outside one, and at arm's length. It is a thing, out there, available to be appraised, and thus fundamentally separate. In this respect, the cognitivist/noncognitivist debate in environmental aesthetics misses the mark I am aiming at in the present paper.

And, yet, this debate is also relevant insofar as the cognitivist insistence on approximately scientific knowledge of environment parallels to some degree the requirement of technical skill for aesthetic enjoyment in NBS, especially NDS. But it is worth noting the restriction of that requirement. As some theorists have pointed out (Carroll), one doesn't need much, if any, scientific knowledge to be emotionally moved by the sight and sound of a powerful waterfall. But one does need a fair degree of technical skill to be able to enjoy the feeling of going over one in a kayak. Knowledge of the environment with which one is interacting can indeed make a difference to the quality of aesthetic experience one encounters, but is only necessary in respect of the direct physical interaction. That is, understanding the forces that cause the water to move as it does-that this volume of water being directed through a channel that wide and rolling over those rocks will exert such-and-such force on my boat so that I will need to paddle so many times on this side with the blade at that angle if I am going to be able to ride the chute the way I want to and have a truly exhilarating experience, as opposed to a bonebreaking disaster-is important for my experience of it if I'm paddling over it, not so much if I am hiking past it. It is possible that my experience would be enhanced in the latter case by better factual knowledge, but it is not necessary. For the kayaker in this case, the aesthetic experience

${ }^{11}$ In Carlson and Berleant, pp. 141-155. 
is one of knowledgeable direct interaction with the environment (the waterfall) itself that is a participation in the natural forces that define the waterfall as the waterfall it is. The passing hiker does not have this specific experience of the waterfall, though she may well have an analogous experience with some other part of the wider environment, e.g., the rocks over which she scrambles in order to avoid going over the waterfall.

\section{Extending Participatory Aesthetics}

Arnold Berleant does not offer the argument I shall do here, but does present similar criticisms while advocating a "participatory aesthetics". He criticises the Cartesian ploy of subduing affect by speculative thought (Berleant 2004, 82) while declaring that "perception...is not just a visual act but a somatic engagement in the aesthetic field" (80) and arguing that we should

"develop a different aesthetic for natural appreciation" than that used for art, "one that acknowledges the experience of continuity, assimilation, and engagement that nature encourages" (81).

"Perceiving environment from within, as it were, looking not at it but being in it, nature becomes something quite different. It is transformed into a realm in which we live as participants, not observers." (83)

Thus Berleant advocates experiencing nature on a modified model of the Kantian sublime, not only in its big dramatic occasions, but gentler engagements as well, for example,

"Canoeing a serpentine river when the quiet evening water reflects the trees and rocks along the banks so vividly as to allure the paddler into the center of a six-dimensional world, three above and another three below; camping beneath pines black against the night sky; walking through the tall grass of a hidden meadow whose tree-defined edges become the boundaries of the earth." (83)

An aesthetics of nature, Berleant concludes, can lead us toward engagement, transforming both our appreciation of nature and the nature of our appreciation (84). The concept of "participatory aesthetics" is one I want to extend to NDS, and NOS in particular. What Berleant is getting at is the idea of an aesthetics that is based in participatory environmental experience and, to some extent, this involves an interaction with that environment, comparable to art installations that require not just disinterested observation at a distance but, at a minimum, passage through them. At the same time, he is advocating the removal of the aesthetic "frame" through which we tend to approach the natural environment, with our contrived look out spots and the search for the perfect photograph. Berleant does not stress so much as I wish to, however, the active physical dynamic of interaction, but is, I think, on the right trail.

The way in which sport is usually appraised aesthetically is from the traditional aesthetic point of view: that of the spectator. Aesthetic writing on natural environments tends to follow this spectatorial stance with theorists differing on the appropriate criteria for appraising 
aesthetic quality of experience for the spectator: what the spectator should know or how the spectator should feel, imagine, etc. in relation to the scene before her. Following Berleant's suggestion, I would counter that the question ought perhaps to be what the "spectator" could be doing, or rather, how the sportsperson might instead be participating in or with the environment.

If we are to take on a more profoundly active or interactive stance with the natural world, evaluating the quality of aesthetic experience will entail an evaluation of a much broader and richer range of sensuous experiences. An apt avenue to such experience is participation in sport with the natural environment. Recall the two prime areas of aesthetic input in sport laid out earlier: the body itself in movement and the body actively engaged with a physical environment. These centres of aesthetic experience are completely lacking in the above theorists' accounts. This is reasonable if the best way to appreciate a natural environment is in fact to withdraw oneself from it in order to appreciate it as something wholly other and detached from oneself. There are some approaches to the natural world for which this would be appropriate and productive, and some of these may even be aesthetic. But to do so is to risk finding nothing in the natural world save ourselves and what we project upon it. If, however, a better way to know or appreciate something is through interacting with it, physical engagement with the physical environment seems a more fruitful option. But interaction isn't only about the other with which one interacts; it is also about oneself in the interacting. Taking all these considerations into account, a profound aesthetic experience of a natural environment is one that is (im)mediated through physically active engagement with that environment. In other words, NOS, and to a lesser degree NSS, which affords both the immediate apprehension of body and natural world through activity and the means and opportunity for informed reflective appreciation. In this respect, NOS provides for a richer aesthetic appreciation of the natural than does NIS, which must shut out a significant portion of the reflective aesthetic, as well as a more intimate appreciation than either a reflective appraisal or passive gaze alone.

\section{In Conclusion}

Excellence in sport, then, may be seen not only as a matter of the exercise of certain technical skills but as the complex product of a range of considerations: not just how far or how quickly one can move oneself or an object through space but, perhaps, how well such movements serve to bring about other goals that can be defined within the sport itself. This last stipulation is significant: it rules out extrinsic goals but allows those that are not separable from the sport, and NOSs are sports that are structured around distinctly aesthetic goals. Thus, to hike is to engage in a sport that by definition incorporates a particular kind of movement, with its set of specific skills, and a particular kind of aesthetic experience, that is, of a natural feature or environment. Such a goal is intrinsic to the sport. Thus, for NOS, natural discovery and aesthetic enjoyment of nature are built in.

This also helps to explain why certain results that possess a paradoxical cast in UBS and NIS are less so for NOS. "It was a great game (race) even though we lost" is perfectly understandable as an expression of aesthetic satisfaction despite defeat, but one that certainly seems to conflict with the constitutive ends of such sports and thus the technical excellence at which they aim. I don't regard this as fatal, as I regard excellence in all sport as complex, but 
the same sort of remark uttered in the context of NOS has considerably less oddness about it. It is often the case that an excellent hike or climb or canoe-trip is also an unsuccessful one-if success is measured in UBS/NIS and sometimes NSS terms: completion of itinerary, hitting all the marks on the map, getting to the summit, and so on. Indeed, one can imagine instances wherein a dogged insistence on fulfilling the schedule would make for a distinctly diminished experience, of both sport movement and aesthetic experience. Fortunately, perhaps, in nature oriented sport one can fail to fulfill these arbitrary, artificial goals and achieve perfection nonetheless. 


\section{Bibliography}

Berleant, Arnold. "The Aesthetics of Art and Nature" [1992], in Carlson, Allen and Berleant, Arnold, Eds. The Aesthetics of Natural Environments. Toronto: Broadview Press, Ltd., 2004: 76-88.

Brady, Emily. Aesthetics of the Natural Environment. Tuscaloosa, Alabama and Edinburgh: University of Alabama Press and Edinburgh University Press Ltd, 2003.

. "Imagination and the Aesthetic Appreciation of Nature" [1998], in Carlson, Allen and Berleant, Arnold, Eds. The Aesthetics of Natural Environments. Toronto: Broadview Press, Ltd., 2004: 156-169.

Carlson, Allen. "Appreciation and the Natural Environment" [1966], in Carlson, Allen and Berleant, Arnold, Eds. The Aesthetics of Natural Environments. Toronto: Broadview Press, Ltd., 2004: 63-75.

. Aesthetics and the Environment: The Appreciation of Nature, Art, and Architecture. London and New York: Routledge, 2000.

Carroll, Noël. "On Being Moved By Nature: Between Religion and Natural History" [1993], in Carlson, Allen and Berleant, Arnold, Eds. The Aesthetics of Natural Environments. Toronto: Broadview Press, Ltd., 2004: 89-107.

Cronon, William. "The Trouble with 'Wilderness', in William Cronon, ed. Uncommon Ground: Rethinking the Human Place in Nature. New York: W.W. Norton, 1996:

Eaton, Marcia Muelder. "Fact and Fiction in the Aesthetic Appreciation of Nature" [1998], in Carlson, Allen and Berleant, Arnold, Eds. The Aesthetics of Natural Environments. Toronto: Broadview Press, Ltd., 2004: 170-181.

Foster, Cheryl. "The Narrative and the Ambient in Environmental Aesthetics" [1998], in Carlson, Allen and Berleant, Arnold, Eds. The Aesthetics of Natural Environments. Toronto: Broadview Press, Ltd., 2004: 197-213.

Hepburn, Ronald. "Contemporary Aesthetics and the Neglect of Natural Beauty" (1966), in Carlson, Allen and Berleant, Arnold, Eds. The Aesthetics of Natural Environments. Toronto: Broadview Press, Ltd., 2004: 43-62.

Heyd, Thomas. "Aesthetic Appreciation and the Many Stories About Nature" [2001], in Carlson, Allen and Berleant, Arnold, Eds. The Aesthetics of Natural Environments. Toronto: Broadview Press, Ltd., 2004: 269-282.

Kierkegaard, Søren. Either/Or Part I. Edited and translated by Howard V. Hong and Edna H. Hong. Princeton: Princeton University Press, 1987. 
. Fear and Trembling/Repetition. Edited and translated by Howard V. Hong and Edna H. Hong. Princeton: Princeton University Press, 1983.

. Concluding Unscientific Postscript to Philosophical Fragments. Edited and translated by Howard V. Hong and Edna H. Hong. Princeton: Princeton University Press, 1992.

Merchant, Carolyn. "Reinventing Eden", in William Cronon, ed. Uncommon Ground: Rethinking the Human Place in Nature. New York: W.W. Norton, 1996: 132-159.

Saito, Yuriko. "Appreciating Nature on its Own Terms" [1998], in Carlson, Allen and Berleant, Arnold, Eds. The Aesthetics of Natural Environments. Toronto: Broadview Press, Ltd., 2004: 141-155.

Slater, Candace. “Amazonia as Edenic Narrative”, in William Cronon, ed. Uncommon Ground: Rethinking the Human Place in Nature. New York: W.W. Norton, 1996: 114-131. 